International Journal of

Environmental Research and

Public Health

ISSN 1660-4601

www.mdpi.com/journal/ijerph

Article

\title{
Fine Particulate Matter Pollution and Hospital Admissions for Respiratory Diseases in Beijing, China
}

\author{
Qiulin Xiong ${ }^{1}$, Wenji Zhao ${ }^{1, *}$, Zhaoning Gong ${ }^{1, \dagger}$, Wenhui Zhao ${ }^{2, \dagger}$ and Tao Tang ${ }^{3, \dagger}$ \\ 1 Urban Environmental Process and Digital Modeling Laboratory, Capital Normal University, \\ Beijing 100048, China; E-Mails: xiong_q1@163.com (Q.X.); gongzhn@163.com (Z.G.) \\ 2 Beijing Municipal Environmental Monitoring Center, Beijing 100044, China; \\ E-Mail: wenhuidiandian@163.com \\ 3 Department of Geography and Planning, State University of New York College at Buffalo, \\ Buffalo, NY 14222, USA; E-Mail: tangt@buffalostate.edu \\ $\dagger$ These authors contributed equally to this work. \\ * Author to whom correspondence should be addressed; E-Mail: zhwenji1215@163.com; \\ Tel.: +86-106-890-3052; Fax: +86-106-890-3052.
}

Academic Editor: Paul B. Tchounwou

Received: 17 August 2015 / Accepted: 12 September 2015 / Published: 22 September 2015

\begin{abstract}
Fine particulate matter has become the premier air pollutant of Beijing in recent years, enormously impacting the environmental quality of the city and the health of the residents. Fine particles with aerodynamic diameters of $0 \sim 0.3 \mu \mathrm{m}, \quad 0.3 \sim 0.5 \mu \mathrm{m}$, and $0.5 \sim 1.0 \mu \mathrm{m}$, from the yeasr 2007 to 2012, were monitored, and the hospital data about respiratory diseases during the same period was gathered and calculated. Then the correlation between respiratory health and fine particles was studied by spatial analysis and grey correlation analysis. The results showed that the aerial fine particulate matter pollution was mainly distributed in the Zizhuyuan sub-district office. There was a certain association between respiratory health and fine particles. Outpatients with respiratory system disease in this study area were mostly located in the southeastern regions (Balizhuang sub-district office, Ganjiakou sub-district office, Wanshoulu sub-district office, and Yongdinglu sub-district office) and east-central regions (Zizhuyuan sub-district office and Shuangyushu sub-district office) of the study area. Correspondingly, $\mathrm{PM}_{1}$ (particulate matter with aerodynamic diameter smaller than $1.0 \mathrm{um}$ ) concentrations in
\end{abstract}


these regions were higher than those in any other regions. Grey correlation analysis results showed that the correlation degree of the fine particle concentration with the number of outpatients is high, and the smaller fine particles had more obvious effects on respiratory system disease than larger particles.

Keywords: fine particulate matter; hospital admissions; respiratory diseases; functional areas; spatial distribution; grey correlation analysis

\section{Introduction}

Though the proportion of fine particulate matter $\left(\mathrm{PM}_{2.5}\right)$ in the global atmosphere is relatively low, it has a great influence on human health [1-3], as well as on the environment and climate. As the adsorptivity of $\mathrm{PM}_{2.5}$ is strong, they easily become the carrier of toxic substances in the air [4]. Those particles can cause respiratory diseases such as colds, asthma, upper respiratory infections, and pneumonia when they are inhaled into the lungs and remain in the blood. Inhalable particulate matter can affect the visibility of city, human health, and global climate during its transmission and transformation [5-9]. Hans et al. [10] evaluated the impact of $\mathrm{PM}_{2.5}$ on the morbidity and mortality of cardiovascular and respiratory diseases in Tallinn using fine spatial resolution and discrete model. Yin et al. [11] analyzed the concentration of inhalable particulate matter and numbers of outpatients with respiratory diseases in Shanghai during haze conditions. Ha et al. [12] analyzed the correlation between respiratory diseases and $\mathrm{PM}_{2.5}$ in Xining according to the numbers of outpatients with respiratory diseases and atmospheric pollution conditions in recent years.

Air pollution, especially $\mathrm{PM}_{2.5}$ in Beijing, has received increasing attention in the past years. Despite the fact that Beijing has become one of the most atmosphere-polluted cities in the world, there has still been a lack of quantitative research regarding the health impact of $\mathrm{PM}_{2.5}$ in Beijing. Among the few scholars who have conducted $\mathrm{PM}_{2.5}$ health impact research, Tang et al. [13] diagnosed the exposure of the residential population and the vulnerable groups of children and elderly people to air particle pollution in urban Beijing. Liang et al. [14] investigated temporal patterns of $\mathrm{PM}_{2.5}$ over a five-year period and utilized the wavelet approach to explore the potential association between $\mathrm{PM}_{2.5}$ and influenza, on the basis of the collected data on hourly ambient PM 2.5 from the years 2007 to 2012 and on monthly human influenza cases during the same period.

The reports about the influence of fine particulate matter on respiratory health mainly discuss the correlation from the viewpoint of epidemiology or toxicology [15-23]. There are few studies related to the correlation between fine particulate matter and respiratory health from the perspective of geography and spatial analysis, especially on the spatial relevance between $\mathrm{PM}_{2.5}$ and respiratory health in Beijing. Therefore, an urban area of Beijing was selected as the research area in the study. Additionally, the relationship between spatial distributions of $\mathrm{PM}_{2.5}$ and numbers of outpatients with respiratory diseases in Beijing from 2007 to 2012 was discussed, using the method of spatial analysis as well as grey correlation analysis. 


\section{Data and Method}

\subsection{Study Area}

In recent years, the rapid economic and social development of Beijing has caught the attention of the world. However, Beijing's ecological environment, and the atmospheric environment in particular, has suffered a certain degree of pollution as a result of the limitation of natural conditions and human activities. For example, the geographic conditions that mountainous regions distribute in the west, north, and northeast work against the spread of atmospheric particulate matter. Moreover, the climate in Beijing is a typical temperate continental monsoon climate with temperature inversion happening frequently. Residents need heating in winter, so a huge amount of coal is burned during the heating period. Thus, it is easy to form atmospheric pollution in Beijing. Over the last 20 years, Beijing has faced a very serious atmospheric pollution problem due to energy consumption, the rapid growth in the number of vehicles, and the invasion of external pollution sources all through the year, especially in winter [24]. The study area is located in the center of Beijing (Figure 1). There are 24 sub-district offices, including 16 in the Haidian District and eight in the Shijingshan District (Table 1). Two large-scale general hospitals are located in the study area whose radiation scope covers all those sub-district offices. Thus, their outpatients' information reflects the local residents' health status.

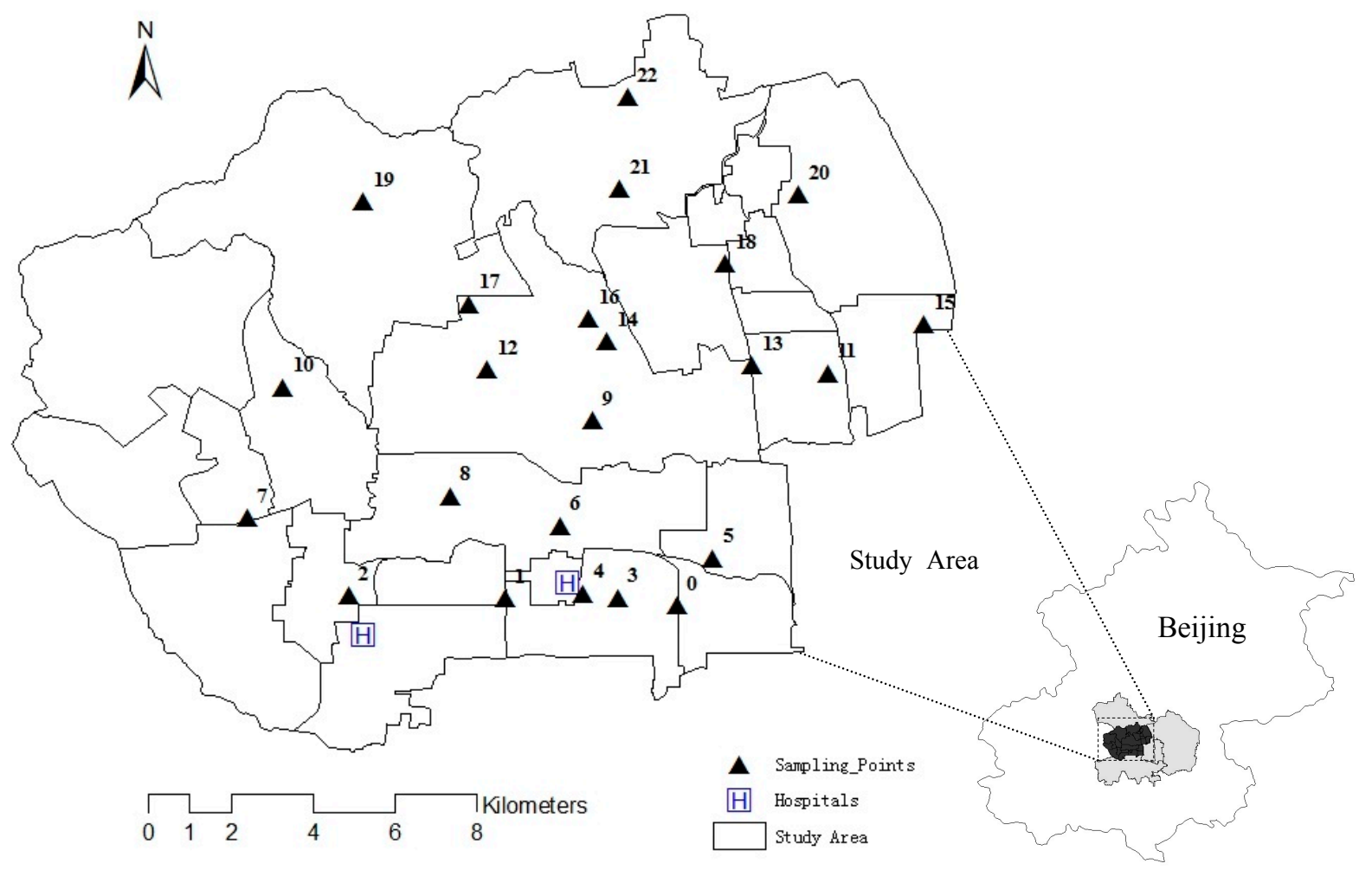

Figure 1. Study area and its location. 
Table 1. Districts in the study area.

\begin{tabular}{cccccc}
\hline FID & ID & Name & District & Population & Post Code \\
\hline 0 & 87 & Balizhuang & Haidian & 128948 & 100036 \\
1 & 88 & Ganjiakou & Haidian & 111596 & 100037 \\
2 & 89 & Wanshoulu & Haidian & 148159 & 100036 \\
3 & 90 & Yongdinglu & Haidian & 37394 & 100039 \\
4 & 91 & Yangfangdian & Haidian & 151419 & 100038 \\
5 & 100 & Qinglongqiao & Haidian & 145286 & 100091 \\
6 & 101 & Xueyuanlu & Haidian & 287124 & 100083 \\
7 & 102 & Xiangshan & Haidian & 35690 & 100093 \\
8 & 103 & Haidian & Haidian & 143513 & 100080 \\
9 & 104 & Qinghuayuan & Haidian & 49072 & 100083 \\
10 & 105 & Yanyuan & Haidian & 36706 & 100080 \\
11 & 106 & Zizhuyuan & Haidian & 222973 & 100044 \\
12 & 107 & Zhongguancun & Haidian & 92900 & 100080 \\
13 & 108 & Shuangyushu & Haidian & 50211 & 100089 \\
14 & 109 & Beitaipingzhuang & Haidian & 136244 & 100088 \\
15 & 110 & Beixiaguan & Haidian & 131720 & 100081 \\
16 & 111 & Bajiao & Shijingshan & 70849 & 100049 \\
17 & 112 & Gucheng & Shijingshan & 62249 & 100043 \\
18 & 113 & Laoshan & Shijingshan & 37774 & 100049 \\
19 & 114 & Babaoshan & Shijingshan & 100731 & 100040 \\
20 & 115 & Wulituo & Shijingshan & 30664 & 100042 \\
21 & 116 & Pingguoyuan & Shijingshan & 81852 & 100041 \\
22 & 117 & Guangning & Shijingshan & 14365 & 100041 \\
23 & 118 & Jinding & Shijingshan & 61963 & 100041 \\
\hline & & & & &
\end{tabular}

\subsection{Data Description}

Data of this study mainly include the following two parts: respiratory disease data and fine particulate matter data.

(1) Data of respiratory disease. Respiratory disease is a kind of familiar disease which exists mainly in the lungs, chest, trachea, and bronchus. The common respiratory diseases include acute upper respiratory infection, acute bronchitis, and so on. The daily respiratory outpatients' information in this study was collected from two large-scale general hospitals which are located in the region (Figure 1). Twelve kinds of respiratory disease cases were collected, including upper respiratory infection (J06), obstructive pneumonia (J16), obstructive emphysema (J43), asthma (J45), chronic bronchitis (J42), chronic obstructive pulmonary disease (J44), chronic tonsillitis (J03), aspiration pneumonia (J03), acute bronchitis ( $\underline{\mathrm{J} 93)}$, acute pharyngitis $(\underline{\mathrm{J} 02)}$, acute laryngitis $(\underline{\mathrm{J} 04)}$, acute purulent tonsillitis ( $\underline{\mathrm{J} 03)}$, and respiratory failure (J96) [25]. The locations were spatialized by the information of addresses and zip codes provided by outpatients. The hospitals started to carry out the electronic medical records system from 2007 on, and data of outpatients with respiratory diseases was gathered from 2007 to 2012 .

The administrative map scale of the study area is 1:25,000. The study area is divided into 24 units by sub-district office (Figure 1). Sub-district office was used as the basic unit while being analyzed. 
According to the sixth population census data in 2010, the population of the Xueyuanlu sub-district office in the Haidian District was the highest, reaching 287,124 (Table 1). Districts with high population density were distributed mainly in the west of the city where a majority of outpatients with respiratory diseases live. Thus, this research has a good representativeness.

(2) Data of fine particulate matter. Handy Laser Particle Counter Kanomax MODEL 3886GEO- $\alpha$ was used to monitor the number concentrations of different sizes $(0 \sim 0.3 \mu \mathrm{m}, 0.3 \sim 0.5 \mu \mathrm{m}$, and $0.5 \sim 1.0 \mu \mathrm{m})$ of fine particles in the study area during 2007 2012. Simultaneously, the spatial coordinates of each sampling point were obtained using a handheld Trimble GPS. MODEL 3886GEO- $\alpha$ can have a 5-channel $(0.3,0.5,1.0,3.0,5.0 \mu \mathrm{m})$ test at the same time, and the test report meets FS-209E, ISO14644-1, and other relevant environmental standards. Provided that the cascade is connected, this instrument will become a multi-point monitoring system. In this case, the sampling time, frequency, and interval can be set according to the need. When the particle number reaches 70 million per cubic meter, the consistency of loss is less than 5\%. The sampling time was December to next January and June to July every year. During the sampling period of each year, the weather conditions were relatively stable, with less wind, no major storms blowing, and no heavy snow. In short, the weather system was relatively stable during sampling periods.

To make the data of the particulate matter representative, sampling points were arranged evenly, extensively, and regularly over different underlying surfaces in Beijing city, whose total number was 23, as shown in Figure 1. The sampling program followed the "Three Sames" principle, i.e. the same height (1.5 $\mathrm{m}$ above the ground), the same time (the sampling time was ensured to be the same), and the same distance $(1.5 \mathrm{~m}$ away from the road). In the meantime, the handheld anemograph (Kestrel 3500) was used to record the temperature, relative humidity, and wind speed of the sampling points. All data acquired in the study area were imported into ArcGIS software in the form of $\operatorname{shp~(a~kind~of~spatial~data~format).~}$

\subsection{Method}

\subsubsection{Spatial Analysis}

Spatial analysis is an important factor of geography and geographic information science which has received more and more attention in geography and its related disciplines [26]. It is the analysis technology that obtains the location, distribution, shape, formation, and evolution information of related geographic objects, as well as one of the core functions of the geographical information system.

Firstly, the particle number concentration data derived from MODEL 3886GEO- $\alpha$ was associated with the spatial coordinates of the sampling sites measured by handheld GPS via the same attribute (object ID). Consequently, particulate matter data was assigned to spatial attributes. Secondly, geocoding analysis was conducted in ArcGIS software. Therefore, the spatial properties of the particulate matter data could form the spatial coordinates, whose projection was to coincide with the administrative demarcation diagrams of Beijing city. Finally, spatial analysis was carried out in the geographic information systems. After all those three steps were finished, the spatial distribution of the particle number concentration as well as its temporal evolution can be simulated. 


\subsubsection{Grey Correlation Analysis}

To study the relationship between fine particulate matter and respiratory disease, the grey correlation method was utilized in this paper. Grey correlation analysis is used to quantize and analyze the development tendency of dynamic procedures by closeness of curve shape. The closer the geometry curve shape is, the greater the correlation of the comparison system is [27-29].

$S_{i j}=\left(x_{i j}^{0}(1), x_{i j}^{0}(2), \cdots, x_{i j}^{0}(n)\right)$ is set as the reference sequence and $S_{i 0}=\left(x_{i 0}(1), x_{i 0}(2), \cdots, x_{i 0}(n)\right)$ is the comparative sequence. The reference sequence reflects the characteristics of the system behavior and the comparative sequence is composed of factors that affect the system behavior. Usually, the initial values of the reference sequence and compared sequence have different units. Thus, it adopts the equalization method in dimensionless treatment before comparison. This is as follows.

$$
\begin{gathered}
\overline{S_{i j}}=\frac{1}{m} \sum_{k=1}^{m} S_{i j}(k) \\
S_{i j}(k) d=\frac{S_{i j}(k)}{\bar{S}}
\end{gathered}
$$

In Equations (1) and (2), $k=0,1, \ldots, m$. Then the correlation coefficient of the reference sequence and compared sequence can be obtained.

$$
\zeta_{i}(k)=\frac{\min _{i} \min _{k}\left|S_{i j}(k)-S_{i 0}(k)\right|+\rho \max _{i} \max _{k}\left|S_{i j}(k)-S_{i 0}(k)\right|}{\left|S_{i j}(k)-S_{i 0}(k)\right|+\rho \max _{i} \max _{k}\left|S_{i j}(k)-S_{i 0}(k)\right|}
$$

In Equation (3), $k=1,2, \ldots, n$. Thus, $\min _{i} \min _{k}\left|S_{i}(k)-S_{0}(k)\right|$ is the minimum value of the two stages and $\max _{i} \max _{k}\left|S_{i j}(k)-S_{i 0}(k)\right|$ is the maximum value of the two stages; $\rho$ is resolution ratio. Its value is between 0 and 1 . Usually, $\rho=0.5$.

Because the number of the correlation coefficient is large, in order to be convenient for comparing, the degree of correlation was calculated to judge the influence between the reference sequence and the compared sequence.

$$
\gamma=\frac{1}{m} \sum_{k=1}^{m} \xi_{i}(k)
$$

In Equation (4), $k=0,1, \ldots, m$.

\section{Results and Discussion}

\subsection{Spatial Distribution of Fine Particulate Matter}

The detailed information about the spatial distribution of $\mathrm{PM}_{1}$ from 2007 to 2012 was shown in Figure 2. In 2007, the most heavily $\mathrm{PM}_{1}$-polluting sub-district offices were Shuangyushu sub-district office and Zizhuyuan sub-district office. Correspondingly, the number of outpatients from these two sub-district offices were higher than those of other sub-district offices. In 2008, the more heavily $\mathrm{PM}_{1}$-polluting sub-district offices were Balizhuang sub-district office, Ganjiakou sub-district office, 
Wanshoulu sub-district office, and Zizhuyuan sub-district office. In 2009 and 2011, the more heavily PM1-polluting sub-district office was Zizhuyuan sub-district office. In 2012, the more heavily PM1-polluting sub-district offices were Babaoshan sub-district office and Zizhuyuan sub-district office.
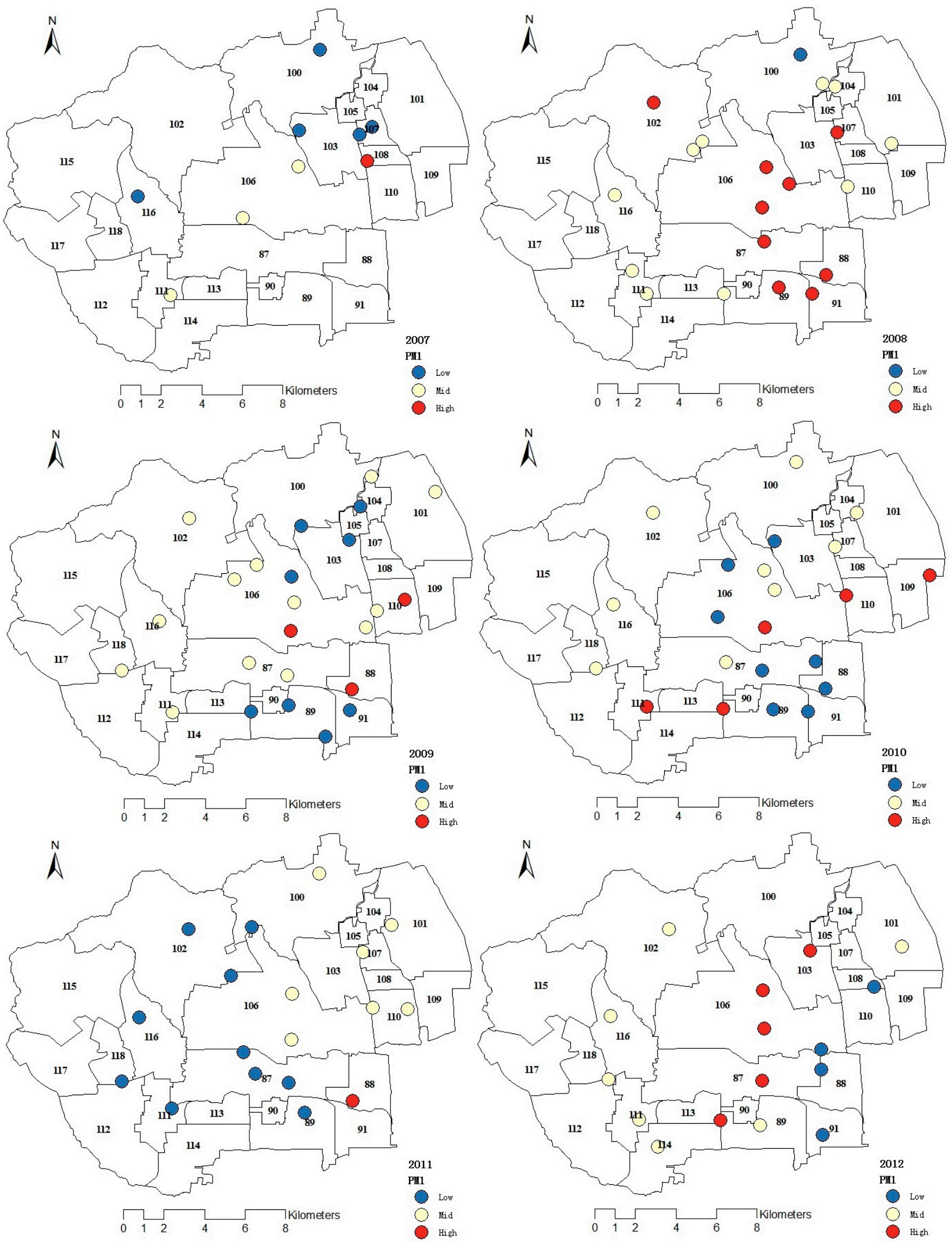

Figure 2. Spatial distribution of $\mathrm{PM}_{1}$ from 2007 to 2012. 


\subsection{Respiratory Outpatients Distribution}

Statistics on the numbers of outpatients in the respiratory department were taken from 2007 to 2012. The statistics variables are shown in Table 2, including Sum, Min, Max, Mean, Median, SD (standard deviation), and RSD (relative standard deviation) of the respiratory outpatients in the study area. According to Table 2, the largest number of the total outpatients (Sum) of all sub-district offices in a year appeared in 2010, reaching as high as 649; the smallest number was in 2007, with only 270. The minimum (Min) values of one single sub-district office were just 0 or 1 . Particularly, there were four sub-district offices in 2008 where no respiratory cases took place. It was likely because the Beijing Olympic Games were held this year, and the ecological environment was better than in other years. The maximum (Max) values ranged from 82 (in 2008) to 153 (in 2011). The average (Mean) values ranged from 11 (in 2007) to 27 (in 2011). The median values ranged from 3 (in 2007) to 9 (in 2011). All these three variables showed an annually increasing trend. SD values ranged from 18.56 (in 2007) to 41.92 (in 2011). RSD was calculated by SD and Mean. All the RSD values were higher than 1.5 except those in 2009 (1.49), which demonstrated that the spatial distribution of outpatients in the study area was quite different during these years. The highest number of outpatients was 153 in the Wanshou Road sub-district office in 2011. This sub-district office is also a high population density area in Beijing.

Table 2. Statistics on respiratory outpatients from 2007 to 2012.

\begin{tabular}{ccccccc}
\hline Statistics Year & $\mathbf{2 0 0 7}$ & $\mathbf{2 0 0 8}$ & $\mathbf{2 0 0 9}$ & $\mathbf{2 0 1 0}$ & $\mathbf{2 0 1 1}$ & $\mathbf{2 0 1 2}$ \\
\hline Sum & 270 & 316 & 582 & 649 & 639 & 623 \\
Min & 1 & 0 & 0 & 1 & 1 & 0 \\
Max & 82 & 82 & 131 & 147 & 153 & 127 \\
Mean & 11 & 13 & 24 & 27 & 27 & 25 \\
Median & 3 & 5 & 9 & 9 & 9 & 8 \\
SD & 18.56 & 22.80 & 36.10 & 41.41 & 41.92 & 38.12 \\
RSD & 1.65 & 1.73 & 1.49 & 1.53 & 1.57 & 1.54 \\
\hline
\end{tabular}

The spatial distribution of outpatients' locations was also attained from the information of outpatients' addresses and zip codes. Results are shown in Figure 3. Overall, the spatial distribution of outpatients showed the following characteristics. Firstly, the spatial distribution of outpatients in different years varied considerably. Secondly, the spatial variation of outpatients was complex. Thirdly, due to the radiation scope of the hospitals, outpatients with respiratory system disease in this study were mainly concentrated in the southeastern regions (Balizhuang sub-district office, Ganjiakou sub-district office, Wanshoulu sub-district office, and Yongdinglu sub-district office) and east-central regions (Zizhuyuan sub-district office and Shuangyushu sub-district office) of the study area. Correspondingly, $\mathrm{PM}_{1}$ concentrations in these regions were higher than those in other regions. In turn, the numbers of outpatients in these sub-district offices heavily stricken by $\mathrm{PM}_{1}$ were higher than those of other sub-district offices. Finally, the incidence of outpatients during 2007 2012 showed an annually increasing trend. 

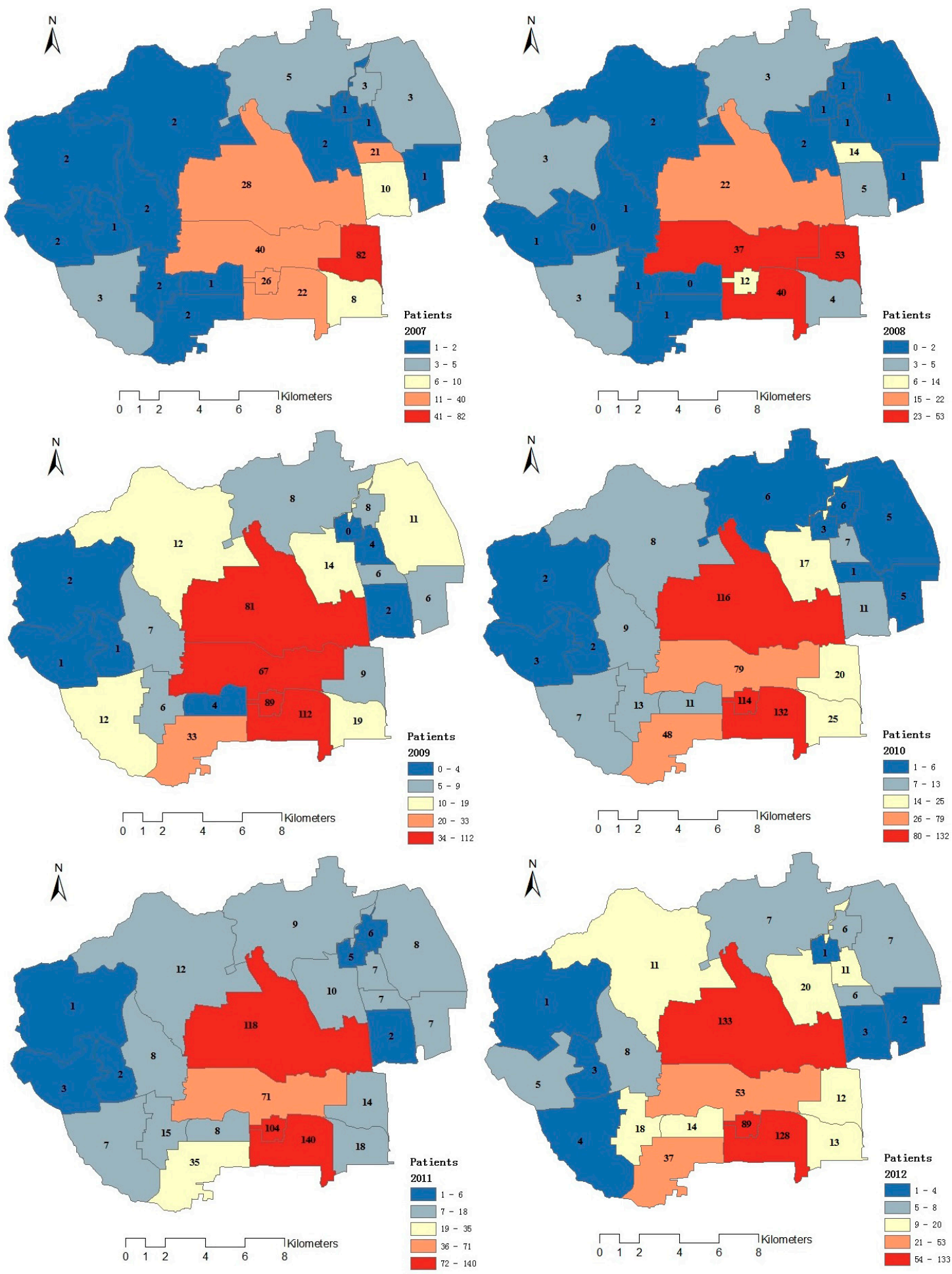

Figure 3. Spatial distribution of outpatients from 2007 to 2012.

\subsection{Grey Correlation Analysis}

Grey correlation analysis was used to analyze the relationship between particulate matter number concentration and the number of outpatients in the study area. Considering the "week effect" of respiratory system diseases and the influence of meteorological factors, DOW (day-of-the-week) was introduced into the grey correlation model along with temperature, relative humidity, and wind speed as a comparative sequence. With the calendar effect and meteorological factors taken, the associations 
from small to large were obtained in Table 3. From Table 3, it is obvious that the impact degree of $\mathrm{PM}_{0.3}$ on the number of outpatients is the largest among the three sizes of particles, except in 2012. The influence degree of $\mathrm{PM}_{0.3}$ on the number of outpatients is the largest, which is 0.8213 (in the years 2009 and 2010) and the influence degree of $\mathrm{PM}_{1.0}$ is the smallest, which is 0.6949 in 2012. Based on the order of correlation degree, it is clear that there is an obvious regularity in the results of the grey correlation analysis during 2007 2012. Overall, the correlation degree order of fine particles was $\mathrm{PM}_{0.3}>\mathrm{PM}_{0.5}>\mathrm{PM}_{1.0}$. It turned out that smaller fine particles had more effect on the cases of respiratory system disease than the larger particles. From the grey correlation analysis, the correlation degree of all fine particle concentration to the number of outpatients is high. It means that fine particulate matter has a great impact on respiratory system disease.

Table 3. Grey correlation degree and its range during 2007 2012.

\begin{tabular}{cccccccccc}
\hline Year & & $\mathbf{2 0 0 7}$ & \multicolumn{3}{c}{$\mathbf{2 0 0 8}$} & \multicolumn{3}{c}{$\mathbf{2 0 0 9}$} \\
\hline PM & $\mathrm{PM}_{0.3}$ & $\mathrm{PM}_{0.5}$ & $\mathrm{PM}_{1.0}$ & $\mathrm{PM}_{0.3}$ & $\mathrm{PM}_{0.5}$ & $\mathrm{PM}_{1.0}$ & $\mathrm{PM}_{0.3}$ & $\mathrm{PM}_{0.5}$ & $\mathrm{PM}_{1.0}$ \\
Correlation degree & 0.7771 & 0.772 & 0.7595 & 0.7467 & 0.7402 & 0.7425 & 0.8213 & 0.8211 & 0.8068 \\
Correlation range & 1 & 2 & 3 & 1 & 3 & 2 & 1 & 2 & 3 \\
\hline Year & & $\mathbf{2 0 1 0}$ & & & $\mathbf{2 0 1 1}$ & & & $\mathbf{2 0 1 2}$ \\
PM & $\mathrm{PM}_{0.3}$ & $\mathrm{PM}_{0.5}$ & $\mathrm{PM}_{1.0}$ & $\mathrm{PM}_{0.3}$ & $\mathrm{PM}_{0.5}$ & $\mathrm{PM}_{1.0}$ & $\mathrm{PM}_{0.3}$ & $\mathrm{PM}_{0.5}$ & $\mathrm{PM}_{1.0}$ \\
Correlation degree & 0.8213 & 0.8099 & 0.7909 & 0.7944 & 0.7825 & 0.7624 & 0.702 & 0.7064 & 0.6949 \\
Correlation range & 1 & 2 & 3 & 1 & 2 & 3 & 2 & 1 & 3 \\
\hline
\end{tabular}

\section{Conclusions}

The paper is an environmental health study that demonstrates how serious fine particle pollution in Beijing is and its possible correlation with hospital admissions for respiratory diseases. The results showed that spatial distributions of fine particles were diverse and there was a certain association between respiratory health and fine particles. The finding is consistent with the results of Professor Tang's research in 2010 [13]. Outpatients with respiratory system diseases in this study were mainly distributed in the southeastern regions (Balizhuang sub-district office, Ganjiakou sub-district office, Wanshoulu sub-district office, and Yongdinglu sub-district office) and east-central regions (Zizhuyuan sub-district office and Shuangyushu sub-district office) of the study area. Correspondingly, $\mathrm{PM}_{1}$ concentrations in these regions were higher than those in other regions. Grey correlation analysis results showed that the correlation degree between all fine particle concentration and the number of outpatients is high, and the smaller fine particles had more obvious effects on respiratory system diseases than the larger particles. It is similar to results from previous research [14,30,31]. This research reveals the serious conditions of fine particle pollution and its environmental health effect in Beijing, China.

\section{Acknowledgments}

This work was supported by the Special Fund for Doctoral Program of Higher (No. 20111102110004), the National Youth Science Fund (No. 41101404), and the Surface Project of the Beijing Municipal Commission of Education Technology Plan (No. KM201110028013). 


\section{Author Contributions}

Wenji Zhao had the original idea for the study and all co-authors designed and performed the experiments. Qiulin Xiong analyzed the data and drafted the manuscript. All authors have read and approved the final manuscript.

\section{Conflicts of Interest}

The authors declare no conflict of interest.

\section{References}

1. Peters, A. Particulate matter and heart disease: Evidence from epidemiological studies. Toxicol. Appl. Pharm. 2005, 207, 477-482.

2. Englert, N. Fine particles and human health-A review of epidemiological studies. Toxicol. Lett. 2004, 149, 235-242.

3. Zhang, M.; Song, Y.; Cai, X. A health-based assessment of particulate air pollution in urban areas of Beijing in 2000 2004. Sci. Total Environ. 2007, 376, 100-108.

4. Mu, Z.; Zhao, J.; Xu, N.; Yao, L.; Li, Y.; Meng, J. Vertical and temporal variation of PM10 in Yanta District, Xi' an during winter. Acta Sci. Circumstantiae 2011, 31, 1509-1516.

5. Zhao, Q.; He, K.B.; Ma, Y.L.; Jia, Y.T.; Cheng, Y; Liu, H.; Wang, S.W. Regional PM pollution in Beijing and surrounding area during summertime. Environ. Sci. 2009, 30, 187-1880.

6. Watson, J.G. Visibility: Science and regulation. J. Air Waste Manage. 2005, 52, 628-713.

7. Chen, R.J.; Chen, B.H.; Kan, H.D. A health-based economic assessment of particulate air pollution in 113 Chinese cities. China Environ. Sci. 2010, 30, 410-415.

8. Wang, S.X.; Hao, J.M. Air quality management in China: Issues, challenges, and options. J. Environ. Sci. 2012, 24, 2-13.

9. Pouliou, T.; Kanaroglou, P.S.; Elliott, S.J.; Pengelly, L.D. Assessing the health impacts of air pollution: A re-analysis of the Hamilton children's cohort data using a spatial analytic approach. Int. J. Environ. Health Res. 2008, 18, 17-35.

10. Orru, H.; Teinemaa, E.; Lai, T.; Tamm, T.; Kaasik, M.; Kimmel, V.; Kangur, K.; Merisalu, E.; Forsberg, B. Health impact assessment of particulate pollution in Tallinn using fine spatial resolution and modeling techniques. Environ. Health 2009, 8, 1-9.

11. Yin, Y.W.; Cheng, J.P.; Duan, Y.S., Wei, H.P.; Ji, R.X.; Yu, J.L.; Yu, H.R. Correlation analysis between the $\mathrm{PM}_{2.5}, \mathrm{PM}_{10}$ which were taken in the hazy day and the number of outpatient about breathing sections, breathing sections of pediatrics in Shanghai. Environ. Sci. 2011, 32, 1894-1998.

12. Ha, H.P.; Yang, L. Analysis of the influence of inhalable particle $\left(\mathrm{PM}_{10}\right)$ to respiratory system disease in Xining. J. Qinghai Environ. 2009, 19, 147-148. 
13. Tang, T.; Zhao, W.; Gong, H.; Li, X.; Zang, K.; Bernosky, J. D.; Zhao, W.; Li, S. GIS spatial analysis of population exposure to fine particulate air pollution in Beijing, China. Environ. Geosci. 2010, 17, 1-16.

14. Liang, Y.; Fang, L.; Pan, H.; Zhang, K.; Kan, H.; Brook, J.R.; Sun, Q. PM 2.5 in BeijingTemporal pattern and its association with influenza. Environ. Health 2014, 13,102-102.

15. Zhao, S.P.; Yu, Y.; Chen, J.B.; Liu, N.; He, J.J. Size distribution properties of atmospheric aerosol particles during summer and autumn in Lanzhou. Environ. Sci. 2012, 33, 687-693.

16. Wang, W.W.; Chen C. A quantitative analysis on spatial distribution of the pollutants in the urban air and their impact factors based on geostatistics and GIS: A case study of Hangzhou city. Geogr. Res. 2008, 27, 241-249.

17. Orru, H.; Maasikmets, M.; Lai, T.; Tamm, T.; Kaasik, M.; Kimmel, V.; Orru, K.; Merisalu, E.; Forsberg, B. Health impacts of particulate matter in five major Estonian towns: Main sources of exposure and local differences. Air Qual. Atmos. Hlth 2011, 4, 247-258.

18. Kuang, C.; Neumann, T.; Norra, S.; Stüben, D. Land use-related chemical composition of street sediments in Beijing. Environ. Sci. Pollut. Res. 2004, 11, 73-83.

19. Han, Y.J.; Kim, T.S.; Kim, H. Ionic constituents and source analysis of $\mathrm{PM}_{2.5}$ in three Korean cities. Atmos. Enviro. 2008, 42, 4735-4746.

20. Ren, Y.J. The case-crossover studies of air particulate matter pollution and cardiovascular disease death. China Environ. Sci. 2007, 27, 657-660.

21. Peacock, J.L.; Symonds, P.; Jackson, P.; Bremner, S.A.; Scarlett, J.F.; Strachan, D.P.; Anderson, H.R. Acute effects of winter air pollution on respiratory function in schoolchildren in southern England. Occup. Environ. Med. 2003, 60, 82-89.

22. Zhang, J.Y.; Meng, H.Y.; Zhang, G.B.; Zhao, W.; Pan, X.C. Relationship between air pollution and daily respiratory system disease mortality in Chaoyang District, Beijing: A time-series analysis. J. Environ. Health 2011, 28, 788-791.

23. Wang, H.R.; Zhai, Q.M. Shen, J. Impacts of air pollutants on the respiratory system diseases in a city. Environ. Sci. Manag. 2011, 36, 54-57.

24. Han, L.H; Zhuang, G.S.; Cheng, S.Y.; Wang, H.Y. Characteristics of re-suspended road dust and its significant effect on the airborne particulate pollution in Beijing. Environ. Sci. 2009, 30, 1-8.

25. 2015 ICD-10-CM Codes for Diseases of the respiratory system. http://www.icd10data.com/ICD10CM/Codes/J00-J99.

26. Zhao, Y.; Kong, Y.F. Geography curriculum: Introduction to spatial analysis. Sci. Geogr. Sin. 2011, 31, 1090-1096.

27. Sun, Y.; Zhang, X.; Cheng, X., Hui, W.; Tan, M.; Chen, J. Gray correlative analysis of the impact from growing urbanization process on pedodiversity in Nanjing area. Acta Geogr. Sin. 2006, 61, 311-318.

28. Liu, Y.S. The changes of fiscal agriculture-supporting expenditure and farmers' income based on grey correlation theory. Asian Agric. Res. 2011, 3, 92-95.

29. Hou, P.Q.; Ren, Y.F.; Wang, X.K.; Ouyang, Z.Y.; Zhou, X. P. Research on evaluation of water quality of Beijing urban storm water runoff. Environ. Sci. 2012, 33, 71-75. 
30. Fuji, T.; Hayashi, S.; Hogg, J.C.; Vincent, R.; Van Eeden, S.F. Particulate matter induces cytokine expression in human bronchial epithelial cells. Am. J. Respir. Cell Mol. Biol. 2001, 25, 265-271.

31. Ketzel, M.; Berkowicz, R.; Hvidberg, M.; Jensen, S.S.; Raaschou-Nielsen, O. Evaluation of AirGIS: A GIS-based air pollution and human exposure modelling system. Int. J. Environ. Pollut. 2011, 47, 226-231.

(C) 2015 by the authors; licensee MDPI, Basel, Switzerland. This article is an open access article distributed under the terms and conditions of the Creative Commons Attribution license (http://creativecommons.org/licenses/by/4.0/). 